\title{
Comparison of Initial Cell Retention and Clearance Kinetics After Subendocardial or Subepicardial Injections of Endothelial Progenitor Cells in a Canine Myocardial Infarction Model
}

Andrea J. Mitchell ${ }^{1,2}$, Eric Sabondjiann ${ }^{1,2}$, Jane Sykes ${ }^{2}$, Lela Deans², Wendy Zhu², Xiangru Lu³, Qingping Feng ${ }^{2,3}$, Frank S. Prato ${ }^{1,2}$, and Gerald Wisenberg ${ }^{2,4}$

${ }^{I}$ Department of Medical Biophysics, University of Western Ontario, London, Ontario, Canada ${ }^{2}$ Lawson Health Research Institute, London, Ontario, Canada; ${ }^{3}$ Departments of Medicine, Physiology, and Pharmacology, University of Western Ontario, London, Ontario, Canada; and ${ }^{4}$ Department of Medicine, University of Western Ontario, London, Ontario, Canada

Neither intravenous nor intracoronary routes provide targeted stem cell delivery to recently infarcted myocardium in sufficient quantities. Direct routes appear preferable. However, most prior studies have used epicardial injections, which are not practical for routine clinical use. The objective of this study was to compare cell retention and clearance kinetics between a subepicardial and a subendocardial technique. Methods: We evaluated 7 dogs with each technique, using ${ }^{111}$ In-tropolonelabeled endothelial progenitor cells and serial SPECT/CT for 15 d after injection. Results: In vivo indium imaging demonstrated comparable degrees of retention: $57 \% \pm 15 \%$ for the subepicardial injections and $54 \% \pm 26 \%$ for the subendocardial injections. Clearance half-lives were also similar at $69 \pm 26$ and $60 \pm 21 \mathrm{~h}$, respectively. Conclusion: This study demonstrates that subendocardial injections, clinically more practical, show clearance kinetics comparable to those of subepicardial injections and will facilitate the ultimate clinical use of this treatment modality.

Key Words: myocardial infarction; stem cell therapy; cell labeling; single photon emission computed tomography

J Nucl Med 2010; 51:413-417

DOI: 10.2967/jnumed.109.069732

N everal articles attest to marked reduction in fibrotic injury after myocardial infarction after stem cell transplantation in rodent models $(1,2)$. Hence, it was hoped that this technique could be applied clinically to improve prognosis. Subsequently, several clinical trials were undertaken with, at best, modest improvement of global or regional left ventricular function and reduction in the extent

Received Aug. 24, 2009; revision accepted Nov. 23, 2009.

For correspondence or reprints contact: Gerald Wisenberg, London Health Sciences Centre, University Campus, 339 Windermere Rd., London, Ontario, Canada N6A 5 A5.

E-mail: gerald.wisenberg@lawsonimaging.ca

COPYRIGHT @ 2010 by the Society of Nuclear Medicine, Inc. of myocardial necrosis (3-6). Although many of these trials were undertaken with an intracoronary injection of cells, an effective means of targeted delivery to the infarct site had not been established. In fact, many of the issues that may play a major role in determining the benefit of cell transplantation-such as the route of cell delivery (intracoronary, direct epicardial, or endocardial), timing of injection after myocardial infarction, and preferable tissue milieu (reperfusion or sustained occlusion)_remain unanswered. Further, a clear association has not been made between the number of cells engrafted, their residence time within myocardium, and the degree of myocardial repair. Because of the small size of an infarct in rodent models, as compared with that of clinical infarcts, many of these issues can likely be addressed only in large-animal models.

Cell tracking may be able to provide answers to some of these questions, at least in terms of establishing the degree of initial cell delivery, viability, and retention at the transplant site. We have shown that radionuclide labeling can be performed, using appropriate doses of radioactivity, without affecting the biologic activity of the cells and still providing sufficient radioactive signal for imaging in a canine model of myocardial infarction (7). Experiments performed in our laboratory indicate that ${ }^{111}$ In released by either viable or nonviable stromal cells is not significantly taken up by these cells, or a rat embryonic cardiomyoblast $\mathrm{H} 9 \mathrm{c} 2$ cell line, and is rapidly cleared from the site of injection (8). Most radioactive signal observed after transplantation remains within viable cells, and from our work we see little evidence that the radioactivity persists in macrophages at the injection site.

We have established a canine model of myocardial infarction that can be used, with SPECT, to track the fate of ${ }^{111}$ In-tropolone-labeled autologous cells after transplantation 
by an epicardial injection (9). Epicardial injections, which would require at the least a minithoracotomy if they were to be applied clinically, are likely not practical for patients with a recent myocardial infarction. Rather, direct endocardial injections via a left ventricular catheter may provide an alternative, but the degree of cell retention would need to be demonstrated as comparable to epicardial injections performed under direct vision. Recently, the literature has suggested that endothelial progenitor cells may be more effective than other marrow or peripheral blood cell lines in promoting cardiac repair after myocardial infarction $(10-12)$. We have chosen to use this cell line for these experiments.

The present study was undertaken to address the following specific issue: are endocardial injections comparable to direct epicardial injections in terms of the fraction of cells initially transplanted and their retention over the first $2 \mathrm{wk}$ ?

\section{MATERIALS AND METHODS}

\section{Animal Preparation}

Fourteen 20- to 24-kg adult female bred-for-research hounds were used. All procedures were approved by the Animal Care Committee of the University of Western Ontario and performed according to the Guide to the Care and Use of Experimental Animals, Canadian Council on Animal Care and Use of Laboratory Animals, National Research Council (13). We used a 2-h left anterior descending coronary artery occlusion and reperfusion model. Seven animals received cells administered under direct vision by an open thoracotomy on the day of infarction. The other 7 received cells administered into the subendocardium using a left

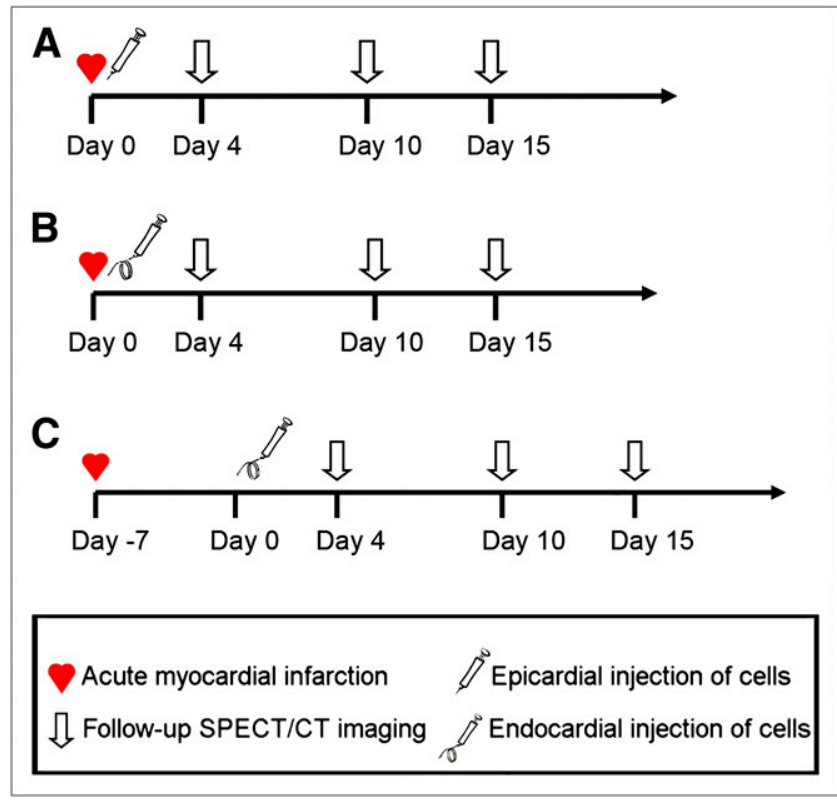

FIGURE 1. Endothelial progenitor cells labeled with ${ }^{111} \mathrm{In}$ were injected by subepicardial injection $(n=7)$ on day of infarction (A), subendocardial injection on day of infarction $(n=4)(B)$, or subendocardial injection at $1 \mathrm{wk}$ after infarction $(n=3)(C)$. Follow-up imaging with SPECT/CT occurred 4,10 , and $15 \mathrm{~d}$ after cell transplantation. ventricular catheter. Four endocardial injections were on the day of the infarction and 3 at $1 \mathrm{wk}$ (Fig. 1).

\section{Cell Preparation}

Thirty milliliters of peripheral blood were harvested from each animal $8 \mathrm{wk}$ before the cell injection. Endothelial progenitor cells were isolated and identified as described by He et al. (14) (Fig. 2). Cell cultures were expanded to approximately $30 \times 10^{6}$ cells and labeled with ${ }^{111}$ In-tropolone (7). Cell viability experiments were conducted to ensure the dose of radiation used did not show any effect on viability or proliferation.

\section{Cell Transplantation}

Endocardial Injections. A 7-French introducer sheath was inserted into the femoral artery, the animals were given 2,000
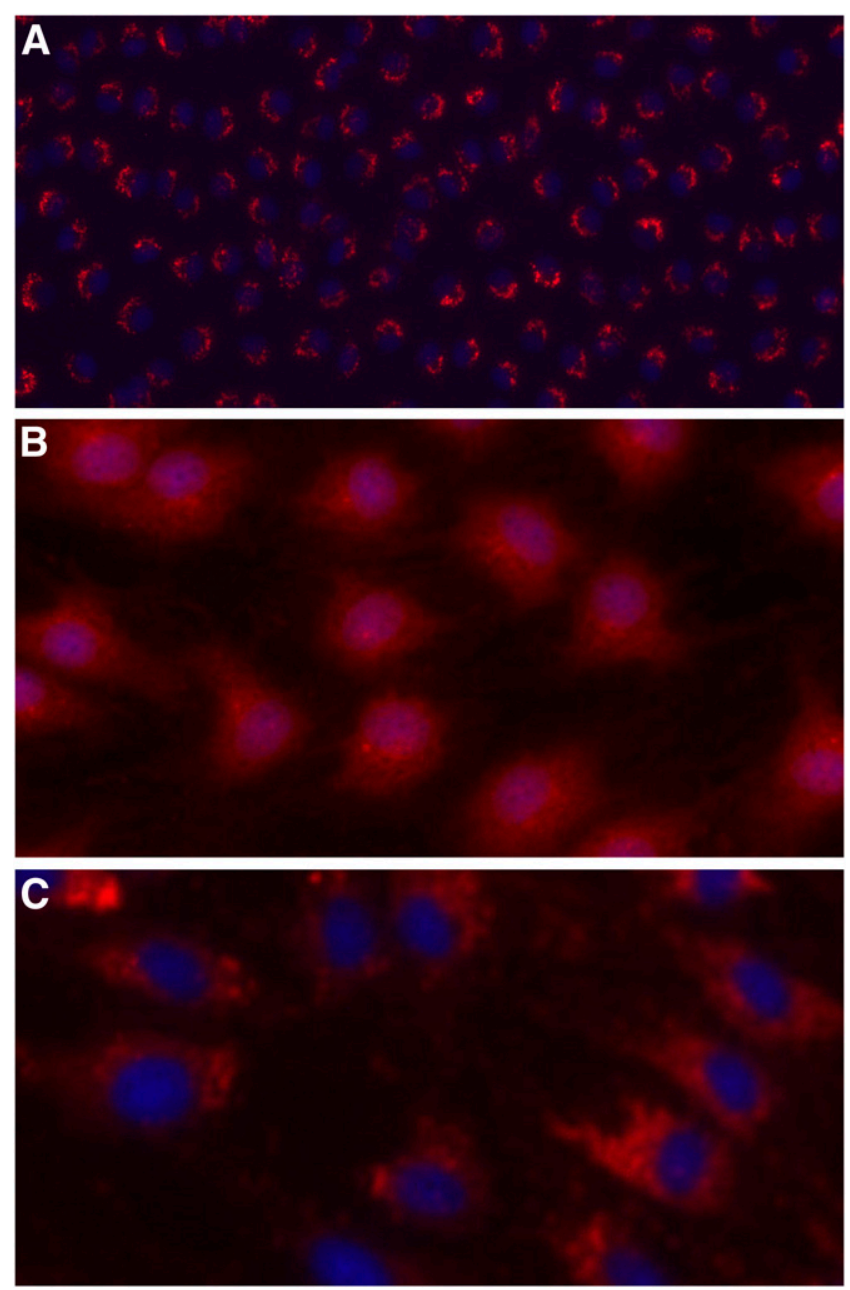

FIGURE 2. Endothelial progenitor cells expressing positive uptake of fluorescence-labeled acetylated low-density lipoprotein (red color; Dil-acetylated low-density lipoprotein; Biomedical Technologies Inc.) and Hoechst (blue color) stain (confocal scanning microscopy; ×200) (A); immunostaining using antibodies against vascular endothelial growth factor receptor 2 (red color; Santa Cruz Biotechnology) and Hoechst (blue color) stain (confocal scanning microscopy; $\times 400)(B)$; and immunostaining using antibodies against von Willebrand factor (red color; Dako Corp.) and Hoechst (blue color) stain (confocal scanning microscopy; ×400) (C). 
units of heparin intravenously, and catheters were flushed with heparinized saline $(10 \mathrm{U} / \mathrm{mL})$. In the angiography suite, with the animal supine, biplane right anterior $\left(30^{\circ}\right)$ and left anterior oblique $\left(60^{\circ}\right)$ contrast ventriculograms (Omnipaque; GE Healthcare) were obtained using a 6-French pigtail catheter. Outlines mapping the left ventricle end-diastolic endocardial contour were drawn by hand on transparencies using the ventriculograms. These contours were used to map each targeted subendocardial injection. Endocardial injections were performed using the Stiletto Endomyocardial Injection System (Boston Scientific) under radiographic fluoroscopic guidance. This system uses a retractable 26-gauge needle, which extends beyond its casing with a length of $3.5 \mathrm{~mm}$. The Stilletto catheter was guided to the endocardium inside a 7-French guiding catheter, which has a radiopaque marker, allowing visualization of when the catheter is perpendicular to the endocardial wall. With confirmation of endocardial contact, the Stilletto catheter was advanced to the edge of the guiding catheter and the triggering button depressed to propel the spring-loaded needle into the myocardium for cell injection. Multiple (8-10) injections within 1-2 cm into the periinfarct region were performed for each animal.

\section{Epicardial Injections}

Cells were injected directly into the periinfarct region (by visual assessment of both discoloration and regional wall motion at the epicardial surface) at multiple sites (8-10) using a 25-gauge needle.

\section{Nuclear Medicine Imaging and Analysis}

Whole-Body Imaging. Canines were transported to the SPECT/ CT (Symbia T6; Siemens) suite, 30-40 min after injection. A whole-body scan was acquired, and the counts for the whole body and region over the heart were calculated and backgroundcorrected; counts have been presented as the heart-to-whole body ratio expressed as percentages (Table 1).

\section{SPECT/Contrast-Enhanced CT}

The SPECT portion consisted of 64 projections $(30 \mathrm{~s} /$ projection, $128 \times 128$ image matrix) and unenhanced CT $(130 \mathrm{kVp}, 15 \mathrm{mAs})$ at end expiration. Fifty $2.5-\mathrm{mm}$ axial image slices were obtained across the heart. Subsequently, a 30-mL bolus of CT contrast (300 mg of iodine/mL; Omnipaque) was injected intravenously and cardiac gated helical CT (130 kVp, $35 \mathrm{mAs})$ was immediately performed using a calcium scoring protocol (15). Follow-up scans were performed at 4,10 , and up to $15 \mathrm{~d}$ after injection. As the ${ }^{111}$ In decayed over time, image acquisition time increased to improve image quality (Fig. 3).

After background correction, the ${ }^{111}$ In projection data were reconstructed with ordered-subset expectation maximization (3 iterations, 16 subsets) incorporating resolution compensation and filtered with a gaussian filter of $5.4 \mathrm{~mm}$ in full width at half maximum. The reconstructed image array was $128 \times 128 \times 128$ (2.7-mm isotropic voxel size). A volume of interest was defined on day 0 images by pixels at least $30 \%$ of the maximum pixel intensity. The mean pixel intensity was fit to a monoexponential function in MATLAB (MathWorks) (Fig. 3), and the half-life in hours was reported (Table 1).

\section{Statistics}

Data are expressed as mean $\pm \mathrm{SD}$. Comparison of the degree of engraftment between the 2 techniques was performed using a univariate ANOVA in SPSS (SPSS Inc.). Statistical significance was set at a $P$ value less than 0.05 .

\section{RESULTS}

Cells were labeled with $0.11 \pm 0.02 \mathrm{~Bq} /$ cell of 111 In. Seven animals received $28 \times 10^{6} \pm 3 \times 10^{6}$ cells by epicardial injection, and 7 animals received $28 \times 10^{6} \pm 5 \times$ $10^{6}$ cells by endocardial injection. The cardiac SPECT/CT showed areas of hypoperfusion in all animals. The initial cell retention was comparable for the subepicardial $(57 \% \pm$ $15 \%)$ and subendocardial $(54 \% \pm 26 \%)$ injections $(P=$ 0.53). The clearance half-lives (Fig. 3A) were also similar at $69 \pm 26$ and $60 \pm 21 \mathrm{~h}$, respectively $(P=0.81)$. Representative images are shown in Figure 4. When the endocardial injections were compared, the half-life of cell clearance at day $0(74.6 \pm 15.3 \mathrm{~h})$ was longer than at week $1(41.3 \pm 0.8 \mathrm{~h})(P=0.015$, power $=0.83)$.

\section{DISCUSSION}

Although intravenous or intracoronary injections of cells seems attractive because of its relative ease, the actual number of cells delivered to the infarct site is minimal in animal studies (16). Direct intramyocardial injections appear more favorable (17), but subendocardial injections would be easier to apply clinically. The forces that influence cell

\begin{tabular}{|c|c|c|}
\hline Group & $\begin{array}{l}\text { Heart-to-whole } \\
\text { body ratio, on } \\
\text { injection day }\end{array}$ & Long half-life (h) \\
\hline \multicolumn{3}{|l|}{$\begin{array}{l}\text { Epicardial } \\
\text { injection, day } 0\end{array}$} \\
\hline Dog 1 & $58 \%$ & 48.44 \\
\hline Dog 2 & * & 59.70 \\
\hline Dog 3 & $51 \%$ & 50.89 \\
\hline Dog 4 & $56 \%$ & 84.39 \\
\hline Dog 5 & $69 \%$ & 40.56 \\
\hline Dog 6 & $32 \%$ & 82.62 \\
\hline Dog 7 & $74 \%$ & 113.31 \\
\hline Mean $\pm S D$ & $57 \% \pm 15 \%$ & $68.6 \pm 25.9$ \\
\hline \multicolumn{3}{|l|}{$\begin{array}{l}\text { Endocardial } \\
\text { injection, day } 0\end{array}$} \\
\hline Dog 8 & $78 \%$ & 55.99 \\
\hline Dog 9 & $72 \%$ & 68.60 \\
\hline Dog 10 & $82 \%$ & 83.62 \\
\hline Dog 11 & $60 \%$ & 90.16 \\
\hline Mean $\pm S D$ & $73 \% \pm 10 \%{ }^{\dagger}$ & $74.6 \pm 15.3^{\ddagger}$ \\
\hline \multicolumn{3}{|l|}{$\begin{array}{l}\text { Endocardial } \\
\text { injection, week } 1\end{array}$} \\
\hline Dog 12 & $44 \%$ & 42.11 \\
\hline $\operatorname{Dog} 13$ & $20 \%$ & 40.49 \\
\hline Dog 14 & $19 \%$ & 41.46 \\
\hline Mean $\pm S D$ & $28 \% \pm 14 \%^{\dagger}$ & $41.3 \pm 0.8^{\ddagger}$ \\
\hline $\begin{array}{l}\text { Total endocardial } \\
\text { mean } \pm S D\end{array}$ & $54 \% \pm 26 \%$ & $60.4 \pm 20.8$ \\
\hline \multicolumn{3}{|c|}{$\begin{array}{l}{ }^{*} \text { Whole-body SPECT image not acquired. } \\
{ }^{\dagger} P=0.004 \text { between cell retention (heart-to-whole body ratio) } \\
\text { for endocardial injection at day } 0 \text { vs. week } 1 \text {. } \\
{ }^{\ddagger} P=0.015 \text { between half-life of cell clearance of endocardial } \\
\text { injection at day } 0 \text { vs. week } 1 .\end{array}$} \\
\hline
\end{tabular}



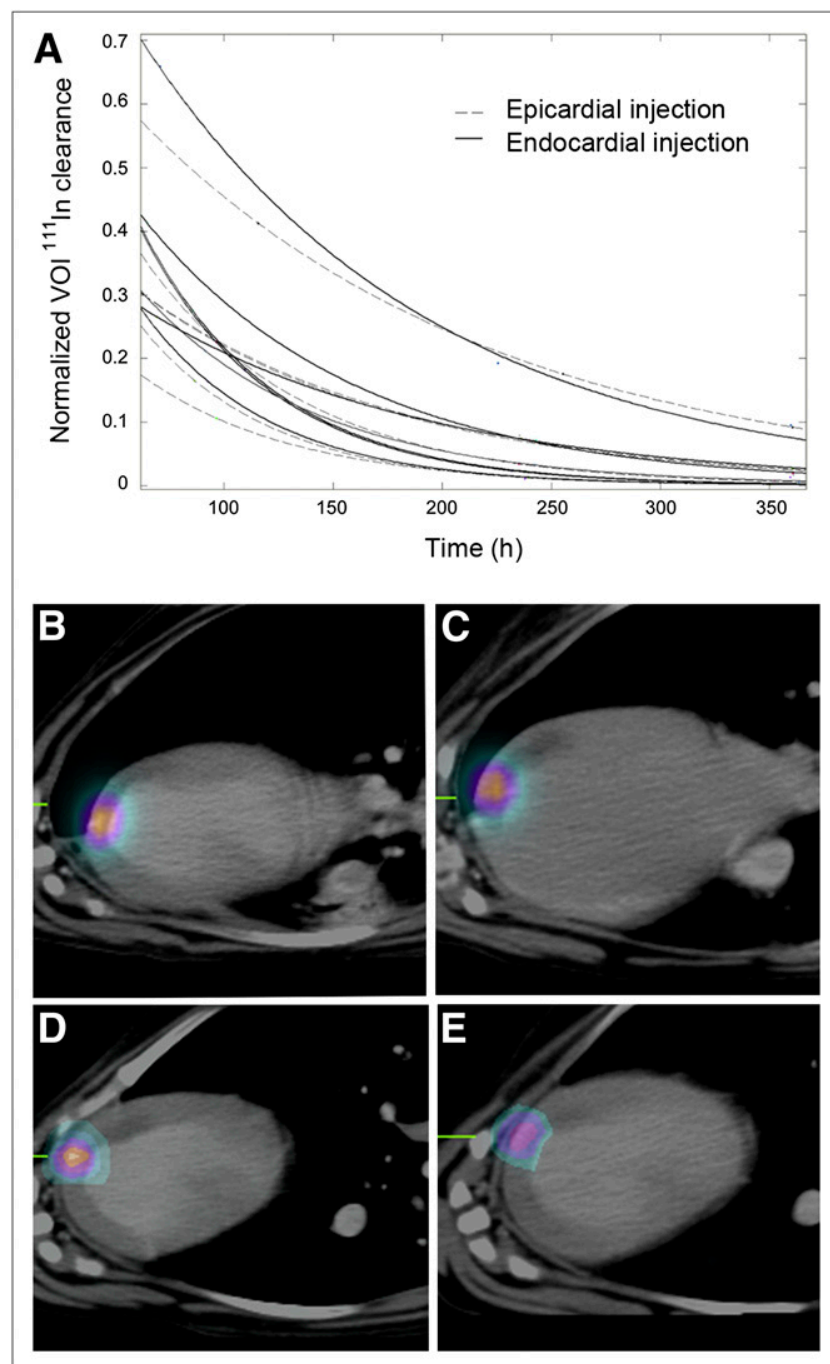

FIGURE 3. (A) SPECT in vivo time-activity curves of ${ }^{111}$ In activity, decay-corrected and fit to monoexponential function, for epicardial and endocardial endothelial progenitor cell injections, from which half-life of cell clearance was calculated. Epicardial injections had clearance half-life of $69 \pm 26 \mathrm{~h}$, and endocardial injections had clearance half-life of $60 \pm 21$ h. Symbols represent normalized raw data. Representative images are shown (B-E) of SPECT scans acquired with increasing acquisition time. Day 0 (30 s/ projection) (B), day 4 (30 s/projection) (C), day10 (120 s/ projection) (D), and day 15 (180 s/projection) (E).

loss with an endocardial injection would, in theory, be different from those affecting an epicardial injection with the cyclic beat-to-beat changes in intramyocardial pressures perhaps producing different effects in the subendocardium versus subendocardium.

Transmural gradients in systolic and diastolic pressure have been reported, demonstrating higher pressures within the subendocardium during systole and lower pressures during diastole relative to the subepicardium and potentially producing transmural differences in contractility $(18,19)$. Subendocardial pressure was greater than intra-
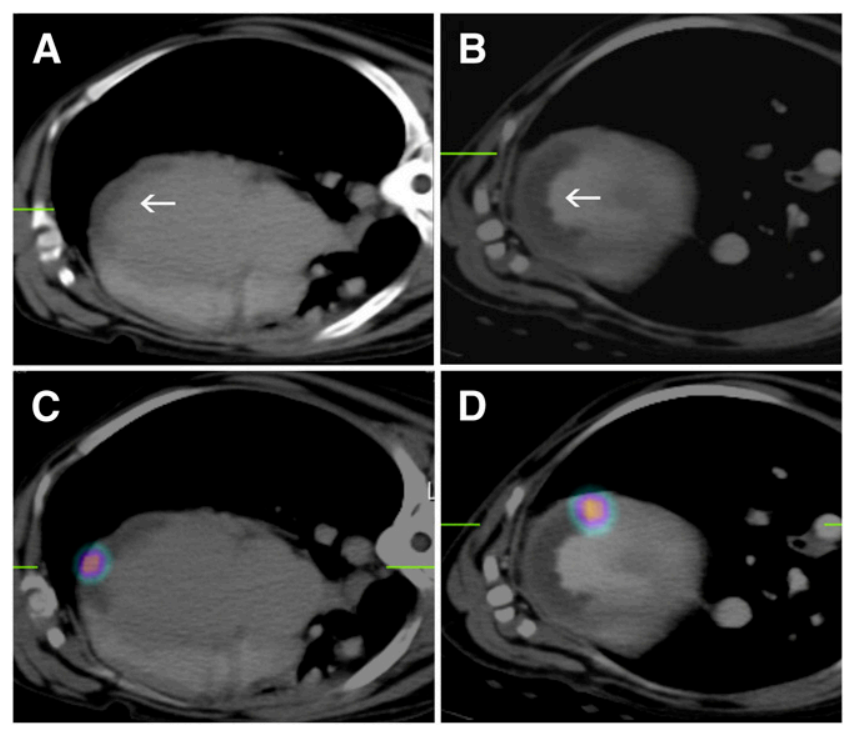

FIGURE 4. Day 0 imaging showing transaxial plane in 2 canine hearts. ( $A$ and $B$ ) Contrast-enhanced CT images, with arrow denoting hypoenhanced region within infarction. (C and D) Contrast-enhanced images fused with SPECT images of transplanted endothelial progenitor cells labeled with ${ }^{111} \mathrm{In}$. Images of first dog (A and C) show cells transplanted by epicardial injection, and images of second $\operatorname{dog}(B$ and $D)$ show cells transplanted by endocardial injection in relation to region of infarction.

cavitary pressure, whereas subepicardial pressure was not (18). These findings suggest several important differences that may affect clearance kinetics of injected material. Grossman et al. demonstrated that retention of neutronactivated microspheres (diameter, $15 \mu \mathrm{m}$ ) in a porcine model was greater after endocardial injection, using our same Stiletto Endomyocardial Injection System, than after epicardial injection. Further optimization of transendocardial delivery suggests that parameters such as needle length and injection volume can improve retention of various injectable materials (20).

We found no significant overall difference between the endocardial and epicardial injection methods in either the initial cell retention or the clearance kinetics, indicating that the injection strategies were comparable. However, although the number of animals is limited, the clearance half-life of cells injected via the subendocardial route at 1 wk was statistically significantly less than when cells were injected by the same route on the day of infarction. Theoretically, when cells die, they may be taken up by macrophages, which invade the infarct area. The time course of macrophage invasion into the canine infarct has been described previously and shown to peak at 1 wk after injury (21). If transplanted cells had died and either free indium that was released from cells or radioactive cell debris was taken up by these macrophages, then one would have expected the apparent cell clearance time to have been prolonged at $1 \mathrm{wk}$ rather than shorter as appears to be the case. 
The efficacy of treatment was not evaluated in these experiments. This study was designed purely to assess the degree of cell retention followed by clearance kinetics. The use of the endocardial approach has been validated as an effective means of cell delivery and can be used in future experiments to assess the optimum timing of injection, as the same animal could potentially receive multiple labeled injections at different times to evaluate clearance kinetics and retention strategies.

\section{CONCLUSION}

The transplanted cell retention and cell clearance kinetics of catheter-based endocardial injections are equivalent to those of direct epicardial injections.

\section{ACKNOWLEDGMENTS}

We thank Michelle Belton and Donna Goldhawk for their assistance with cell cultures, Kim Blackwood for her assistance with the labeling procedures, and Yves Bureau for his assistance with the statistical analysis. We also thank Anna MacDonald and Jahangir Charania for their contribution involving the endocardial injection of cells. We are thankful for the financial support from the Heart and Stroke Foundation of Ontario, the Canadian Institutes for Health Research, and the Ontario Ministry of Research and Innovation. We also acknowledge the support of Boston Scientific, which provided the Stilletto catheters.

\section{REFERENCES}

1. Orlic D, Kajstura J, Chimenti S, et al. Bone marrow cells regenerate infarcted myocardium. Nature. 2001;410:701-705.

2. Nishida M, Li TS, Hirata K, Yano M, Matsuzaki M, Hamano K. Improvement of cardiac function by bone marrow cell implantation in a rat hypoperfusion heart model. Ann Thorac Surg. 2003;75:768-773.

3. Meyer GP, Wollert KC, Lotz J, et al. Intracoronary bone marrow cell transfer after myocardial infarction: eighteen months' follow-up data from the randomized, controlled BOOST (BOne marrOw transfer to enhance ST-elevation infarct regeneration) trial. Circulation. 2006;113:1287-1294.
4. Schächinger V, Assmus B, Britten MB, et al. Transplantation of progenitor cells and regeneration enhancement in acute myocardial infarction: final oneyear results of the TOPCARE-AMI trial. J Am Coll Cardiol. 2004;44:16901699.

5. Schächinger V, Erbs S, Elsaesser A, et al. Intracoronary bone marrow-derived progenitor cells in acute myocardial infarction. N Engl J Med. 2006;355:1210-1221.

6. Yousef M, Schannwell CM, Koestering M, Zeus T, Brehm M, Strauer BE. The BALANCE study clinical benefit and long-term outcome after intracoronary autologous bone marrow cell transplantation in patients with acute myocardial infarction. J Am Coll Cardiol. 2009;53:2262-2269.

7. Jin Y, Kong HF, Stodilka RZ, et al. Determining the minimum number of detectable cardiac-transplanted in-111-tropolone-labelled bone-marrow-derived mesenchymal stem cells by SPECT. Phys Med Biol. 2005;50:4445-4455.

8. Blackwood KJ, Lewden B, Wells GR, et al. In vivo SPECT quantification of transplanted cell survival after engraftment using ${ }^{111} \mathrm{In}$-tropolone in infarcted canine myocardium. J Nucl Med. 2009;50:927-935.

9. Wisenberg G, Lekx K, Zabel P, et al. Cell tracking and therapy evaluation of bone marrow monocytes and stromal cells using SPECT and CMR in a canine model of myocardial infarction. J Cardiovasc Magn Reson. 2009;11:11.

10. Badorff C, Brandes RP, Popp R, et al. Transdifferentiation of blood-derived human adult endothelial progenitor cells into functionally active cardiomyocytes. Circulation. 2003;107:1024-1032.

11. Kawamoto A, Gwon HC, Iwaguro H, et al. Therapeutic potential of ex vivo expanded endothelial progenitor cells for myocardial ischemia. Circulation. 2001;103:634-637.

12. Kawamoto A, Tkebuchava T, Yamaguchi JI, et al. Intramyocardial transplantation of autologous endothelial progenitor cells for therapeutic neovascularization of myocardial ischemia. Circulation. 2003;107:461-468.

13. Canadian Council on Animal Care. Guide to the Care and Use of Experimental Animals. Ottawa, Ontario, Canada: Canadian Council on Animal Care, 1993.

14. He H, Shirota T, Yasui H, Matsuda T. Canine endothelial progenitor cell-lined hybrid vascular graft with nonthrombogenic potential. J Thorac Cardiovasc Surg. 2003; 126:455-464.

15. Holz A, Lautamaeki R, Sasano T, et al. Expanding the versatility of cardiac PET/ CT: feasibility of delayed contrast enhancement CT for infarct detection in a porcine model. J Nucl Med. 2009;50:259-265.

16. Chin BB, Nakamoto Y, Bulte JWM, Pittenger MF, Wahl R, Kraitchman DL. In111 oxine labelled mesenchymal stem cell SPECT after intravenous administration in myocardial infarction. Nucl Med Commun. 2003;24:1149-1154.

17. Hou D, Youssef EAS, Brinton TJ, et al. Radiolabeled cell distribution after intramyocardial, intracoronary, and interstitial retrograde coronary venous delivery: implications for current clinical trials. Circulation. 2005;112:I150-I156.

18. Stein PD, Marzilli M, Sabbah HN, Lee T. Systolic and diastolic pressuregradients within the left-ventricular wall. Am J Physiol. 1980;238:H625-H630.

19. Sabbah HN, Marzilli M, Stein PD. The relative role of subendocardium and subepicardium in left-ventricular mechanics. Am J Physiol. 1981;240:H920-H926.

20. Grossman PM, Han ZG, Palasis M, Barry JJ, Lederman RJ. Incomplete retention after direct myocardial injection. Catheter Cardiovasc Interv. 2002;55:392-397.

21. Dewald O, Ren GF, Duerr GD, et al. Of mice and dogs: species-specific differences in the inflammatory response following myocardial infarction. Am J Pathol. 2004;164:665-677. 